\title{
Factors contributing to students' satisfaction with direct observation of procedural skills in the school of nursing sciences at the University of Zambia
}

\author{
Martha Mbewe*1, Natalia Mbewe ${ }^{1}$, Catherine M. Ngoma ${ }^{2}$ \\ ${ }^{1}$ Department of Basic and Clinical Nursing Sciences, School of Nursing, University of Zambia, Lusaka Zambia \\ ${ }^{2}$ Department of Midwifery, Women's and Child Health, School of Nursing, University of Zambia, Lusaka Zambia
}

Received: March 19, 2020

DOI: $10.5430 /$ jnep.v10n9p47

\author{
Accepted: May 20, 2020 \\ Online Published: May 31, 2020 \\ URL: https://doi.org/10.5430/jnep.v10n9p47
}

\begin{abstract}
Direct observation of procedural skills is an evidence-based assessment tool used for assessing competence in the practical procedures that nursing students undertake during clinical placement. Having knowledge about students' satisfaction with their educational issues is very important as it helps both faculty and students to achieve educational goals. However factors that may influence student satisfaction with this method of assessment are not known in the school of nursing sciences at the University of Zambia. The purpose of this study was to investigate factors influencing student satisfaction with direct observation of procedural skills in order to get students views on this assessment tool. A cross sectional quantitative survey was used on ninety two (92) conveniently sampled final year undergraduate nursing students. Data were collected using a validated self-reported questionnaire and analysed using IBM SPSS Version 20. Fisher's exact tests were used to determine association between student satisfaction and the independent variables. A $p$-value of $\leq .05$ was considered statistically significant. Major findings revealed that poor clinical environment $98.9 \%$ and faculty non availability $98 \%$ influenced student's satisfaction negatively. Other significant associations where clinical experiences, and feedback, with $p \leq .05$. In conclusion, the major factors that influenced student satisfaction included poor clinical environment which was not conducive for assessments as it lacked many essential medical surgical supplies and non-availability of faculty in the clinical area who were needed to provide feedback, guidance and supervision to the students. Improving the clinical environment, ensuring faculty availability in order to provide timely and constructive feedback may help students achieve their learning objectives. Direct observation of procedural skills still remains an appropriate tool to assess student clinical competence. However, further research and development of cheap, less stressful and economic methods of clinical evaluation to blend with this tool is required in the school of nursing sciences.
\end{abstract}

Key Words: Student satisfaction, Direct observation, Procedural skills, Clinical assessment, Clinical competence

\section{INTRODUCTION}

Having knowledge about students' satisfaction with their educational issues is very important as it helps both faculty and students to achieve educational goals. ${ }^{[1]}$ In their review on students' satisfaction in higher education, Salinda et al. in Sri Lanka defined students' satisfaction as a short-term attitude resulting from an evaluation of students' educational experience, services and facilities. ${ }^{[1]}$

In nursing education, it is the ultimate goal of each nursing

\footnotetext{
*Correspondence: Martha Mbewe; Email: martha.mbewe@unza.zm; Address: Department of Basic and Clinical Sciences, School of Nursing Sciences, The University of Zambia, Lusaka, Zambia.
}

Published by Sciedu Press 
programme to prepare nursing students become clinically competent nurses. ${ }^{[2]}$ Clinical competence has been defined as "habitual and judicious use of communication, knowledge, technical skills, clinical reasoning, emotions, values and reflection in daily practice for the benefit of individuals and community being served". [3] Competencies are gained through pre-service education, continuous nursing education in-service training, and work experience. ${ }^{[4]}$ According to WHO, 2013 competence has been recognized as a core component of professional standards and a major determinant of provider performance as represented by conformance with various clinical, non-clinical, and interpersonal standards. ${ }^{[5]}$ Many certifying bodies, both globally and locally, consider clinical competence as an attribute expected of every practising nurse to demonstrate proficiency in the appropriate use of procedural skills. ${ }^{[2,6]}$

\subsection{Overview of direct observation of procedural skills (DOPS) assessments}

DOPS a tool commonly used in workplace-based assessment worldwide is used for assessing competence in the practical procedures that student nurses undertake in the clinical area. ${ }^{[6]}$ As opposed to many other assessments in medical education, these assessments do not occur in artificial settings, but take place as part of the daily work. Workplace-based assessments offer the opportunity to provide trainees with immediate feedback on their performance. Therefore, they play an important role in competency-based medical education. ${ }^{[7]}$

DOPS involves the assessment of a student's communication, professional skills and attitude which will provide evidence of appropriate everyday clinical competences as they interact with patients in the real world. ${ }^{[8]}$ According to the school of nursing sciences curriculum description, DOPS is done whilst the student undertakes the activity ensuring that they are making satisfactory progress in the clinical area. ${ }^{[6]}$ Two different assessors conducts these assessments and cover a wide range of procedures. The procedure being observed takes 20-30 minutes. The assessor thereafter spends 5-10 minutes providing immediate feedback and completes the assessment form with the student present. The assessment is performed against the standard expected at the end of the student's current stage of training. ${ }^{[2,6]}$ Assessors can be senior staff nurses, registered nurses, or other healthcare professionals competent in the area being assessed (e.g. doctors and midwives). No prior knowledge or approval of the student is needed by the assessor from the university but brief information about the standard required for each stage of training guided by the clinical objectives to be achieved via the assessment is given. The assessment process is led by both the student nurse and the assessor who chooses the proce- dure for assessment. Key result area to focus the assessment are outlined on the DOPS assessment form which must be completed by the assessor following observation with the student present. The outcome of the assessment is a global professional judgement of the assessor that the student has completed the task to the expected standard at that stage. This judgement could be stated as: Satisfactory-meaning the student meets the standard overall and can proceed to the next level or unsatisfactory meaning the student needs to repeat the assessment before progressing to the next level. Aspects of performance that are good as well as those that need improvement are discussed with the student. Furthermore, areas for development are also identified, agreed and recorded on the DOPS form.

Student assessment is an important issue in nursing education. ${ }^{[6]}$ It is necessary to use objective, valid and reliable assessment methods that are appropriate to the learning objectives and domain. ${ }^{[9]}$ In a systematic review on DOPS conducted by Naghma in 2013 on validity, reliability, feasibility, acceptability and educational impact of DOPS it was revealed that DOPS was found to be a useful tool for assessment of procedural skills. ${ }^{[10]}$

Equally in a study conducted by Hengameh et al. in 2015 at the University of Medical Sciences, Terran in Iran, it was revealed that using DOPS improved the students' scores in clinical procedures. ${ }^{[11]}$ However, despite DOPS having being considered as the most effective and evidence based commonly used clinical evaluation method by many scholars, it has a number of challenges. ${ }^{[12,13]}$ It is believed that DOPS is a stressful evaluation, has time limitation for participants, and also has bias between assessors. ${ }^{\text {[] }}$ Other researchers feel that DOPS is only possible when sampling a fraction of what is needed to be produced in a nurse and play a judgemental role rather than a developmental role. ${ }^{[14]}$ This implies that DOPS is subjective as the assessor may just observe and judge a fraction of the performance of the student. For example a student checking a patient's temperature may perform the task very well without explaining the procedure and its relevance for the patient to understand. The assessor may only concentrate on observing the performance of the procedure forgetting other aspects.

\subsection{Student satisfaction with DOPS in the School of Nursing Sciences}

As earlier mentioned, having knowledge about students' satisfaction with their educational issues is very important as it helps both faculty and students to achieve educational goals. ${ }^{[1]}$ If students are able to achieve their educational objectives in the clinical areas, they become competent practitioners. ${ }^{[15]}$ In clinical assessment, student satisfaction is an 
individual overall subjective evaluation of experience during clinical assessment as well as the perception of the gap between what is done and the expected specific objective to be achieved. ${ }^{[15]}$ There are a number of factors that may influence student satisfaction. Identification of these factors is important as it may help in suggesting good ways of boosting the student's performance and confidence. Giving the students an opportunity to voice out their opinions about the quality of education or assessments they do, can be seen as part of broader commitment to the institution and student participation in educational planning as well as learning processes. ${ }^{[16]}$ The nursing students' satisfaction is considered as an important factor of such assessment, contributing to any potential reforms in order to optimize the learning activities and achievements within clinical settings. Therefore, satisfaction could be used as an important contributing factor towards the development of better clinical learning environments in order to satisfy the needs and expectations of students. ${ }^{[13]}$

The school of nursing sciences established in 1976 at the University of Zambia mostly uses DOPS method for both formative evaluation to check on the extent to which students have learnt in the clinical area and summative evaluation to confirm the competences achieved in the clinical area. Formative assessments can highlight specific procedural strengths and weaknesses, allowing performance enhancing feedback and objective setting. The school has been offering degree programs at undergraduate and postgraduate levels to registered nurses (in-service) after obtaining their diploma and also the direct entrants (pre-service) from high school over a period of five years on full time. Students are allocated to different clinical areas throughout their training to acquire the relevant nursing skills after theory component in class. At the end of each allocation students are assessed using DOPS method for formative assessments while OSCE is used in the final examination. These assessments are to determine the skills the student has acquired during a particular allocation. ${ }^{[6]}$ As already described, the student performs a procedure on a real patient they have interacted with in the clinical area and is observed by an experienced assessor who reviews the student's performance using a structured check list or rating scale. The assessor provides feedback to the trainee, which allows the trainee, identify learning needs and plan for future learning opportunities. ${ }^{[6]}$ These assessments are done for both formative and summative evaluation for a student to move to the next level or complete a level. Both the assessor and the student are required to sign the completed DOPS clinical assessment form.

However, the DOPS clinical assessment method has not been evaluated at SONS and neither is it known whether students and their assessors are satisfied with this method of assessment or not. There is need also to identify the factors contributing to students' satisfaction as they are the ones being exposed to this method of assessment. Evidence has shown that the traditional clinical assessment method (DOPS) is unreliable in testing students' performance and has a wide margin of variability between one examiner and the other. ${ }^{[17]}$ It is also believed that feedback oriented clinical evaluation methods can promote learning in addition to evaluating the difficult issues in traditional students' evaluation. ${ }^{[11]}$

Although DOPS has been investigated in various educational respects, there is a limited number of studies exploring the nursing students' point of view from the standpoint of their satisfaction with DOPS on a worldwide basis. ${ }^{[17]}$ Therefore, the researcher decided to conduct a scientific inquiry that will help to identify factors contributing to student satisfaction with the DOPS methods of assessment as no study has been done in Zambia before.

\section{Methods}

\subsection{Study design}

This cross-sectional study design was guided by a modified version of the Keaveney and Young customer satisfaction model of 1997. This particular one was selected because it considers satisfaction as a function of the extent to which students' expectations about the clinical assessments are met with positive confirmations of their expectations leading to higher levels of satisfaction. ${ }^{[18]}$ This model incorporates a comprehensive set of independent variables and self-reported experiential assessments to predict performance, which in return is related to student satisfaction. The model relates to the students and administrative unit of SONS, on the aspects that student experience purely depends on what the department is responsible for providing. Student's experience in an institution is based on the following: connection with the faculty, advising staff, the environment and also the interactions in the classroom. ${ }^{[14]}$ Jaradeen et al. 2012 in their study on student satisfaction with nursing program in Jordan once said that if students have positive experience, they are more satisfied as compared to the students who have negative experiences. ${ }^{[16]}$

\subsection{Study setting}

The study was done in the School of Nursing Sciences at the University of Zambia in Lusaka. The school has been offering undergraduate nursing degree programmes since 1976 and in 2004 postgraduate degrees at masters level was introduced. The school is situated at the University Teaching Hospitals. The University Teaching Hospitals is the largest tertiary health institution in the country made up of five dif- 
ferent hospitals offering a wide range of health services to clients from all over the country. This is where students from the school of nursing sciences as well as surrounding nursing colleges and university students do their clinical placements and clinical assessments.

\subsection{Study population}

The study population included 92 final year undergraduate BSc nursing students in the School of nursing sciences. This population group was conveniently selected as the group had been assessed using the DOPS clinical assessment method during training and had completed most of the assessments in their training as outlined in the curriculum at this level. The undergraduate degree program is five years. Two types of students are enrolled. The direct entrants straight from high school do five years while the in-service which are registered nurses with diplomas join in the fourth year after doing the diploma at colleges for three years since they already have a basic qualification. This university offers an innovative mixed curriculum model where students learn first in class and then sent to various clinical areas for hospital based education.

\subsection{Data collection}

Data were collected using a validated self-reported questionnaire which was developed by the researcher after reviewing the literatures and other related tools. The tool had five sections with both open and closed ended number of questions that helped to answer the study objectives. These questions included how satisfied students were with the following variables; clinical environment, clinical experiences, faculty availability during clinical learning, feedback after the DOPS clinical assessment method, clinical staff availability and clinical staff attitudes. Students rated their views using a five point likert scale ranging from 1-5 as a measure of satisfaction. This tool outlined the degree of satisfaction whereas 4-5 meant that they were satisfaction while 1-3 meant that they were not satisfied. On the factors that may influence student satisfaction, questions were asked in various areas of the variables which include the DOPS clinical assessment method process, feedback, clinical experiences, equipment, faculty availability and the clinical staff attitude. The clinical environment was assessed by the use of a modified clinical environment assessment form as outlined by the University of Zambia revised Clinical Practicum Handbook. Participants filled in the responses on their own after giving consent.

\subsection{Validity and reliability}

Validity and reliability of the instrument are key components of a study as they intel that data collected is a true reflection.
Construct validity of the tool in this study was ensured by asking participants to answer the same questions in the questionnaire. Its validity was also determined by computing the Content Validity Ratio (CVR) and Content Validity Index (CVI). The outcome of the tests (CVR and CVI) showed that questions scored 0.80 and 0.82 respectively based on the experts' panel opinions and pilot study results. The tool further underwent a reliability coefficient (Cronbach's Alpha) test for likert responses and obtained a value of 0.85 showing that it was reliable.

Pre-testing of the instrument was done on the fourth year students who were still undergoing clinical placements and were about to do end of allocation assessment using the DOPS. Most of the responses were ideal and the experts review reported minimal adjustments in the construction of sentences and grammar which were attended to in the final instrument.

\subsection{Ethical consideration}

Ethical clearance was obtained from the University of Zambia Biomedical Research Ethics Committee (UNZABREC). Written permission to conduct the study was also sought from the Dean School of Nursing Science. The purpose of the study and the research process was explained to the participants who were later requested to give their consent in written. The issues of privacy, anonymity and confidentiality were ensured by excluding the name of the participant from the questionnaire and that no other person except the research team members had access to filled questionnaires. Participants were further informed that participation was voluntary and that they were free to withdraw without any consequences or punishment. They were further assured that their responses will neither affect their relationship with the faculty nor their grades or performance in school.

\subsection{Data analysis and presentation of findings}

After sorting out the questionnaires, categorization and codes were assigned manually and entered on data master sheet. There after data were analyzed using IBM SPSS Statistical software for Windows Version 20.0. Students' satisfaction, clinical environment, faculty availability during teaching in the clinical area, clinical staff attitude and clinical experiences were variables under consideration. Univariate analysis of student satisfaction and the factors associated with student satisfaction was carried out to describe the variables. Bivariate analysis of student satisfaction and each of the independent variables was carried out to ascertain association. Fisher's exact tests were used to determine association between student satisfaction and the independent variables. A $p \leq .05$ was considered statistically significant. The findings were presented in tables and figures. 


\section{RESULTS}

The main objective of the study was to identify factors contributing to students' satisfaction with direct observation of procedural skills in the school of nursing sciences at the University of Zambia. 92 final year undergraduate nursing students participated in the study. Therefore the results presented below are factors contributing to students' satisfaction with direct observation of procedural skills in the school of nursing sciences at the University of Zambia. The results are presented in figures and tables as outlined below.

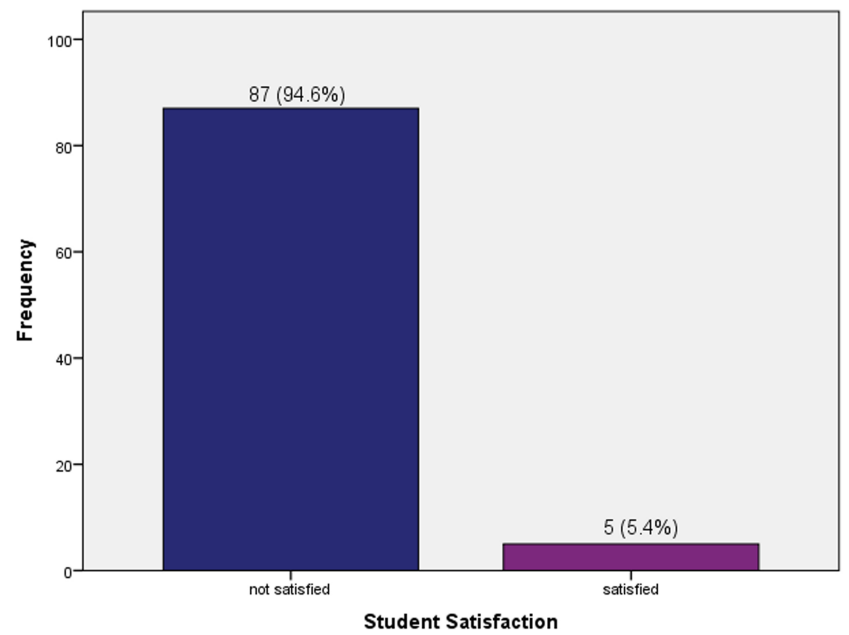

Figure 1. Student satisfaction with the DOPS assessment method $(\mathrm{N}=92)$

As shown in Figure 1 the majority 87 (94.6\%) of the respondents were not satisfied while only $5(5.4 \%)$ were satisfied with the DOPS clinical assessment method.

As shown in Table 1, overwhelmingly $98.9 \%$ (91) of the participants reported poor clinical environment while only $1(1.1 \%)$ reported good clinical environment. Almost all the $98 \%$ (90) participants reported non availability of faculty when teaching in the clinical area except $2 \%$ (2) who reported faculty availability. The majority of the $81(88.0 \%)$ reported that feedback was untimely while $12 \%$ (11) reported that feedback was timely. Majority $95.7 \%$ (88) of the participants reported negative staff attitude while only $4.3 \%$ (4) reported positive staff attitude. Most of the participants 96.7\% (89) reported having had bad experiences with DOPS while only $3.3 \%$ (3) reported having good experiences.

As shown in Table 2, majority of the students were not satisfied with the following all the variables.

As shown in Table 3, Fisher's Exact Test (2-sided), * indicates significant $p$-value at $p \leq .05$, except for clinical staff attitude.

Published by Sciedu Press
Table 1. Factors contributing to Student satisfaction with the DOPS clinical assessment method $(n=92)$

\begin{tabular}{lcc}
\hline Variable & Frequency & Percent (\%) \\
\hline Feedback & 81 & 88.0 \\
Untimely & 11 & 12.0 \\
Timely & 92 & 100 \\
Total & & \\
Clinical Environment & 91 & 98.9 \\
Poor & 1 & 1.1 \\
Good & 92 & 100 \\
Total & & \\
Faculty availability when learning & \\
Not available & 88 & 95.7 \\
Available & 4 & 4.3 \\
Total & 92 & 100 \\
Staff attitude & & \\
Negative & 90 & 98 \\
Positive & 2 & 2 \\
Total & 92 & 100 \\
Clinical experiences & & \\
Bad & 89 & 96.7 \\
Good & 3 & 3.3 \\
Total & 92 & 100 \\
\hline
\end{tabular}

Table 2. Students' satisfaction with variables $(n=92)$

\begin{tabular}{lll}
\hline Variable & Frequency & Percent (\%) \\
\hline Clinical environment & & \\
Not satisfied & 90 & 98 \\
Satisfied & 2 & 2 \\
Total & 92 & 100 \\
Clinical experience & & \\
Not satisfied & 89 & 96.7 \\
Satisfied & 3 & 3.3 \\
Total & 92 & 100 \\
Faculty availability when learning & \\
Not satisfied & 90 & 98 \\
Satisfied & 2 & 2 \\
Total & 92 & 100 \\
Feedback & & \\
Not satisfied & 81 & 88 \\
Satisfied & 11 & 12 \\
Total & 92 & 100 \\
Clinical staff attitude & & 95.7 \\
Not satisfied & 88 & 100 \\
Satisfied & 4 & \\
Total & 92 & \\
\hline
\end{tabular}


Table 3. Association between student satisfaction with the DOPS clinical assessment method and factors $(n=92)$

\begin{tabular}{|c|c|c|c|}
\hline \multirow[b]{2}{*}{ Variable } & \multicolumn{2}{|c|}{ Student satisfaction } & \multirow[b]{2}{*}{$p$-value } \\
\hline & $\begin{array}{l}\text { Not satisfied } \\
\text { n (\%) }\end{array}$ & $\begin{array}{l}\text { Satisfied n } \\
\text { (\%) }\end{array}$ & \\
\hline \multicolumn{4}{|c|}{ Clinical environment } \\
\hline Poor & $87(95.6 \%)$ & $4(4.4 \%)$ & $* .054$ \\
\hline Good & $0(0.00 \%)$ & $1(100.0 \%)$ & \\
\hline \multicolumn{4}{|c|}{ Clinical experience } \\
\hline $\mathrm{Bad}$ & $86(96.6)$ & $3(3.4)$ & $* .007$ \\
\hline Good & $1(33.3)$ & $2(66.7)$ & \\
\hline \multicolumn{4}{|c|}{ Feedback after DOPS } \\
\hline Untimely & $79(97.5)$ & $2(2.5)$ & $* .011$ \\
\hline Timely & $8(72.7)$ & $3(27.3)$ & \\
\hline \multicolumn{4}{|c|}{ Faculty availability when learning } \\
\hline Not available & $85(96.6)$ & $3(3.4)$ & *.014 \\
\hline Available & $2(50.0)$ & $2(50)$ & \\
\hline \multicolumn{4}{|c|}{ Clinical staff attitude } \\
\hline Negative & $86(95.6 \%)$ & $4(4.4 \%)$ & .106 \\
\hline Positive & $1(50.0 \%)$ & $1(50 \%)$ & \\
\hline
\end{tabular}

\section{Discussion}

The discussion is based on the factors contributing to student satisfaction with direct observation of procedural skills in the school of Nursing Sciences at the University of Zambia.

The main objective of our study was to identify factors contributing to students' satisfaction with DOPS.

\subsection{Overview of student satisfaction}

Student satisfaction is the ability of students being able to achieve their objectives and feeling good with what they are doing. ${ }^{[13]}$ Satisfaction plays a major role in determining the originality and accuracy of a system especially the educational system because the higher the level of satisfaction the higher the level of students' grooming their skill development and course knowledge. ${ }^{[13]}$ Having knowledge about students' satisfaction with educational issues is very important to help both faculty and students achieve their educational goals. In the clinical area, if students are able to achieve their educational objectives, it enhances their confidence and satisfaction. ${ }^{[15]}$ In clinical assessment, student satisfaction is an individual overall subjective evaluation of experience during clinical assessment as well as the perception of the gap between what is done and the expected specific objective to be achieved. In other words, student satisfaction is the student's fulfilment. ${ }^{[19]}$

Satisfaction is, however, a relative measure which research literature shows, may be influenced by many factors that should be considered. ${ }^{[15]}$ Traditionally students' overall satisfaction with their educational experiences has been measured by a simple 'yes or no' question, or with one question assessing the degree of overall satisfaction. ${ }^{\text {[9] }}$ Since satisfaction plays an important role in learning and skill acquisition, we can reinforce positive factors and convert the negative ones of the current evaluation status by assessing students' attitudes to promote their satisfaction. So, having knowledge about students' satisfaction with educational issues is very important to help the university to achieve educational goals. ${ }^{[9]}$

Before identifying the factors contributing to student satisfaction, this study investigated the general students' satisfaction with the DOPS assessment method at SONS. The study showed that an overwhelmingly ninety four point six percent (94.6\%) of participants were not satisfied with the DOPS clinical assessment method while only $5.4 \%$ were satisfied with the DOPS clinical assessment method (see Figure 1). The reasons for the students being not satisfied in the current study included non-availability of the faculty in the clinical area during teaching sessions as reported by $96.6 \%$ of the students, poor clinical environment coupled with inadequate equipment and shortages of medical surgical supplies to use during the DOPS assessment, bad clinical experiences which include uncaring attitude of clinical staff who are not willing to help them. Generally students complained of the process to be stressful as the clinical area had a lot of shortages in terms of supplies and time limitation. Contrary to Sahebalzamani et al. (2012) ${ }^{[20]}$ whose study showed that a high percentage of teachers and students are very satisfied with evaluation with DOPS, multiple researchers have seen the students' dissatisfaction in their evaluation status and the results of the clinical evaluation. However, Sahebalzamani \& Jahantigh, 2012 argued that the students are satisfied when assessed by those with more knowledge level. ${ }^{[20]}$ The current study' findings are also in line with the results for a systematic review conducted by Erfani Khanghahi M, Ebadi Fard Azar F in 2018. Their review reported that the major strengths of DOPS evaluation method are providing feedback to the participants, promoting independence and practical skills during assessment. However, it was noted that there were reports of the evaluation being stressful, time limiting for participants, and biases between assessors as the main drawbacks of this method. ${ }^{[21]}$

\subsection{Factors contributing to students' satisfaction with DOPS}

As earlier mentioned satisfaction is a relative measure which research literature shows, may be influenced by many factors that should be considered. ${ }^{[13]}$ The implementation of any assessment tool is basically dependent on the acceptance of 
students. The present study revealed that, faculty availability, clinical experiences, clinical environment and feedback, had a strong association with student satisfaction with DOPS assessment method (see Table 1). Meaning that if improvements are made in the DOPS assessment process, faculty are available in the clinical areas, and give the necessary support, students' experiences will be good and this will in turn lead to their satisfaction with the DOPS assessment method. These findings are in line with the studies conducted by Franz ${ }^{[17]}$ and Mntambo ${ }^{[19]}$ in South Africa.

In this study, the clinical staff attitude had no association with students' satisfaction with DOPS assessment method (see Table 3). Despite this factor not being statistically significant, most of the students reported not being satisfied with it and should not be ignored. Students reported stressful experiences, subjectivity in the awarding of marks as some of them where just shown marks without explanation, time limitation and lack of proper guidance on how to conduct themselves during the assessment.

Variabilities were noted on how the assessment is conducted. Generally in this method of assessment, student should be allowed to choose a client on their own with whom they have interacted which does not happen. Students reported being forced to do procedures even on a client they didn't prepare for. This in turn led to them not being satisfied with the process. This is similar to what was reported by Masoumeh et al. (2018) ${ }^{[18]}$ in their systematic review of evidence on DOPS evaluation method. They reported that satisfaction with DOPS method was found to be moderate in medical education. Some of the contributing factors cited in the review included: stressful evaluation, time limitation for participants, and bias between assessors as the main drawbacks of this method.

\subsubsection{Clinical staff attitude}

Clinical staff's attitude refers to the way the clinical staff responds and treats the students that are undergoing their clinical experience in the clinical areas. ${ }^{[21]}$ The clinical learning process aims to promote the integration of theory into clinical practice with the nurse teacher in the coordinator role. ${ }^{[2]}$ This calls for a mutual relationship between students and the clinical staff to enhance learning. In instances where there is no good relationship between students and clinical staff, it could result in tension and deterioration of work conditions and decreased student satisfaction. ${ }^{[22]}$

In this study, $95.6 \%$ of the students reported that the clinical staff attitude was bad. Most of them cited assessors intimidating students, underrating them and giving them poor marks. This is in line with the study conducted by Mntambo ${ }^{[19]}$ in South Africa and Hoseini et al. ${ }^{[9]}$ in Iran. The intimidation faced by students may lead to poor performance and luck of confidence. In a similar research study done by Evridiki et al. (2016) ${ }^{[15]}$ on nursing students' satisfaction of the clinical learning environment at the Cyprus University of Technology, the findings reported that students felt that supervisory relationship was one of the most influential factor in their satisfaction with the clinical learning environment. ${ }^{[15]}$ However to help solve this problem, SONS has embarked on capacity building trainings of assessors where the faculty is oriented on how to be good examiners and assessors without making the student uneasy.

\subsubsection{Clinical environment}

Another factor influencing student satisfaction revealed in this study was the clinical environment. Clinical environment encompasses all that surround the students while practising or providing nursing care and these include; the availability of functional different equipment, staff, patients, nurse mentors and nurse teachers. ${ }^{[22,23]}$

Activities that take place in the clinical environment should allow students to achieve their objectives. ${ }^{[24,25]}$ Above all students develop their professional self-image in the clinical area and this helps them to go from being able to achieve various tasks to becoming a nurse who understands what their role entails and someone who is an independent and competent practitioner. ${ }^{[26,27]}$ Furthermore, Khosravi et al. (2010) emphasised that the students in clinical settings should have an appropriate professional behaviour, establish an appropriate interaction with the patients, prioritize the problems, have the basic knowledge about clinical methods, perform the care procedures correctly, and apply critical thinking. ${ }^{[23]}$

In our study, the overall response on the clinical environment was that majority (95\%) of the participants reported poor clinical environment (see Table 2). Among the reasons reported to describe the poor clinical environment were that the clinical areas had inadequate equipment to use and had a critical shortage of medical surgical supplies. Staff shortages also were cited as students were left alone to discover things for themselves. Equally faculty members from the SONS were not available to guide and focus their objectives according to the level of practice. These findings are in line with studies done by Hoseini et al. ${ }^{[9]}$ in Iran, Mntambo ${ }^{[19]}$ in South Africa and Espeland and Indrehus ${ }^{[28]}$ in Norway.

\subsubsection{Clinical experience}

On clinical experience is what students go through as they practice in the clinical areas. Students' experiences are said to be good if they are given an opportunity to interact with patients, do procedures with all resources needed for the procedure are available and participate in clinical decision making. ${ }^{[29,30]}$ In our study majority $96.6 \%$ of the students 
reported to have had bad experiences related to shortages of supplies, staff and equipment (see Table 1). These findings concur with a study conducted by Mntambo ${ }^{[19]}$ in South Africa, when they studied Students 'clinical experiences. It was reported that good clinical experience boost students' performance and morale. Most of the contributing factors to bad clinical experiences reported by students included critical shortages of medical surgical supplies, inadequate equipment and non-availability of qualified assessors. This is a true reflection as the University Teaching Hospitals were students do their practical are funded by the government and most of the time funds are not available leading to critical shortages. To this effect, the government through the Ministry of Health have introduced clinical placement fee as a measure of cost sharing where all students are paying for their clinical placement. Funds realised from these fees helps in the purchasing of medical surgical supplies for daily use by students. The challenge is that the fees are too high making it difficult for students to pay for the recommended number of weeks they are supposed to spend in the clinical area.

\subsubsection{Feedback}

Another notable finding on the factors influencing student satisfaction with DOPS assessment method was feedback. Feedback is information about the result of a performance, usually in the context of an observed performance of a skill. It occurs when a student is offered insight into what he or she actually did as well as the consequences of his or her actions. In this study, majority $90.8 \%$ (79) of the respondents who were not satisfied with feedback process and revealed that feedback is untimely (see Table 1). It has been observed that the standard for giving feedback is not adhered to in the school of nursing sciences hence most of the assessors delay to give immediate feedback. Students reported receiving feedback weeks or months after the assessment has been done contrary to the standard that say immediate feedback after DOPS assessment should be given. ${ }^{[7]}$

Studies in Norway ${ }^{[28]}$ and South Africa ${ }^{[19]}$ have revealed that untimely feedback lead to increased levels of anxiety among students and others may continue doing wrong things without knowing what is right. Equally respondents in this study reported being anxious and restless as they wait for the DOPS assessment results. Students reported fears of repeating the same mistakes in the final examination as they would not know the right way to do some procedures without feedback. Previous studies are in agreement with our study findings as they have also revealed that following guidelines for giving useful feedback may help to reduce student's anxiety, improve performance, and increase morale. The University of Zambia recently reviewed the progression regulations and have stated that students should be given feedback on time before writing their examinations. ${ }^{[8,31]}$

\subsubsection{Faculty availability}

Not forgetting to mention, faculty availability was another notable revelation of this study. Faculty plays various roles in DOPS assessment method which includes a constant presence, coordinator, liaison person and the assessor. ${ }^{[8]}$ This study revealed that the faculty from the school are not available in the clinical area and if they are to be present, it is only during assessments. Almost all the students 96.6\% reported the absence of the faculty in the clinical area (see Table 1). Nursing teachers must be in charge of clinical practice because they are the ones ultimately responsible for learning in the clinical practice. ${ }^{[32]}$ Thus, it is in the clinical area that students must relate theory to practice, learn the necessary technical and interpersonal skills, make clinical judgments, become socialized into the profession and begin to appreciate its values and ethics. ${ }^{[32]}$ The development of competent practice is a primary goal for nursing education. To demonstrate this competence, graduates must be able to practice in the "real word". [32]

This was in agreement with a study conducted by Franz and Anthea $^{[17]}$ in South Africa which revealed that $70 \%$ of the students felt that teachers should be approachable, helpful to provide student nurses with necessary support and try to foster student nurses' self-esteem. Non availability of faculty in the clinical area could be attributed to the reason that SONS has inadequate staff to assess and supervise the students as the school is currently using part time demonstrators, lecturers and tutors to help mitigate the shortage of staff in the clinical areas. As earlier mentioned there is no provision at the University's establishment for full time clinical lectures to monitor students, supervise and couch the students. The school of nursing sciences are currently advocating for positions of clinical lecturers to be included in the university establishment. Students need constant presence of the teacher to guide them as they perform procedures on their patients. Faculty availability in the clinical area will help students be focused and do what is right.

\section{Conclusion}

Indeed satisfaction is a relative measure which research literature shows, may be influenced by many factors that should be considered. The present study revealed that the major factors that influenced student satisfaction with DOPS in the school of nursing sciences at the University of Zambia were poor clinical environment, and non-availability of faculty ( $p$ $<.05$ ). If improvements are made in the DOPS assessment process, faculty are available in the clinical area, and give the necessary support, students' experiences will be good and 
this will in turn lead to their satisfaction. Creating conducive environment in the clinical for students is of paramount importance as it is likely to increase student' satisfaction which will lead them to perform well and help them achieve their objectives in attaining the required competence. There is need for the school of nursing sciences to collaborate with the hospital management so as to meet the requirements ideal for the students to practice well. The school of nursing sciences should be conducting check-ups to identify the areas of needs in the clinical area in order to make the learning experience of students fruitful. Cost sharing measures should be enhanced to help cushion the shortages of supplies while students are on attachments. DOPS still remains an appropriated tool to assess student clinical competence but can be strengthened by blending it with other clinical assessment methods like OSCE. However, further research and development of new methods of evaluation to blend with DOPS is required in the school of nursing sciences.

\subsection{Implications}

The current study' implication is that factors influencing student satisfaction with the DOPS assessment method at the SONS has been known i.e. majority $94.6 \%$ of the students at the SONS are not satisfied with the DOPS method of clinical assessment due to poor clinical environment, bad clinical experiences, untimely feedback and non-availability of faculty when teaching in the clinical area. There is a need to look into these areas that affect student satisfaction by providing a conducive environment for students to achieve their learning objectives in the clinical areas.

The current study has added to the body of knowledge by revealing the factors contributing to student satisfaction with this particular method of assessment at the SONS. By adding to the body of empirical knowledge, the identified factors contributing to student satisfaction with DOPS should be considered by others using the same method of assessment. These findings will help to direct the SONS finding means to enhance better ways of making clinical assessments ideal by meeting all the requirements and perhaps even changing ways of clinical assessments.

\subsection{Limitation of the study}

Limited data from scholarly nursing journals made the search for information difficult as most of the studies were just concentrating on the DOPS methods only with no regards to student satisfaction with the method. However other medical fields (e.g. medical students, pharmacy, radiology, physiotherapy and general education) in general have done a number of studies on student satisfaction with DOPS. Furthermore the study used a self-report method to collect data which has a number of limitations. The sample size was too small as it only involved the final year students instead of the whole School. This is the first time a research on factors contributing to student satisfaction with the DOPS assessment method has been conducted in Zambia and the number of respondents was approximately $20 \%$ of the total number of students in the school of nursing sciences which is just a small proportion of the University of Zambia making it difficult to generalize the findings.

\section{CONFLICTS OF INTEREST Disclosure}

The authors declare that there is no conflict of interest.

\section{REFERENCES}

[1] Weerasinghe S, Lalitha S, Fernando RLS. Students' Satisfaction in Higher Education Literature. American Journal of Educational Research. 2017; 5(5): 533-539.

[2] General Nursing Council of Zambia. Registered Nursing Curriculum. GNC. Lusaka Zambia. 2010.

[3] Epistein RM, Hundert EM. Defining and Assessing Professional Competence. J. Am. Med. Association (JAMA). 2007; 287(2): 226235. PMid:11779266 https://doi.org/10.1001/jama.287. 2 .226

[4] Black BP. Professional Nursing: Concepts \& Challenges E-Book, 9th Edition, Elsevier; 2020.

[5] World Health Organization. Transforming and Scaling up Health Professional Education and Training. Policy Brief on Regulation of Health Professions Education. 2013. Available from: http: //whoeducationguidelines.org/sites/default/files/u ploads/whoeduguidelines_PolicyBrief_Regulation.pdf

[6] The University of Zambia. Bachelors of Science in Nursing Curriculum. UNZA, Lusaka, Zambia. 2014.
[7] Lorwald AC, Lahner FM, Nouns ZM, et al. The educational impact of Mini-Clinical Evaluation Exercise (Mini-CEX) and Direct Observation of Procedural Skills (DOPS) and its association with implementation: A systematic review and meta-analysis. PLoSONE. 2018; 3(6): e0198009. PMid:29864130 https ://doi.org/10.1 371/journal pone. 0198009

[8] The University of Zambia. Clinical Practicum Handbook. UNZA, Lusaka, Zambia. 2014.

[9] Hoseini, et al. Comparison of Midwifery Students' Satisfaction with DOPS and Current Methods in Evaluation of Procedural Skills in Mashhad Nursing and Midwifery Schools. Iran. Journal of Nursing and Midwifery Research. 2013; 18: 94-100.

[10] Naeem N. Validity, Reliability, Feasibility, Acceptability and Educational Impact of Direct Observation of Procedural Skills (DOPS). Journal of the College of Physicians and Surgeons Pakistan. 2013; 23(1): 77-82.

[11] Hengameh H, Afsaneh R, Morteza K, et al. The Effect of Applying Direct Observation of Procedural Skills (DOPS) on Nursing Students' Clinical Skills: A Randomized Clinical Trial. Glob J Health 
Sci. 2015; 7(7): 17-21. PMid:26153199 https ://doi.org/10.5 539/gjhs.v7n7p17

[12] Rafiee G, Moattari M, Nikbakht AN, et al. Problems and challenges of nursing students' clinical evaluation: A qualitative study. Iran J Nursing Midwifery Res. 2014; 19(1): 41-49.

[13] Papastavrou E, Dimitriadou M, Tsangari H, et al. Nursing students' satisfaction of the clinical learning environment: a research study. BMC Nurs. 2016; 15: 44. PMid:27436992 https ://doi.org/10 .1186/s12912-016-0164-4

[14] Obano HC. Student's Motivation and level of Satisfaction; A case of Inholland University of Applied Sciences, Aeronautical Engineering Department, Delft Holland. 2012. Available from: http: //www.theseus.fi/handle

[15] Papastavrou E, Dimitriadou M, Tsangari H, et al. Nursing students' satisfaction of the clinical learning environment: a research study. BMC Nurs. 2016; 15: 44. PMid:27436992 https ://doi .org/10 .1186/s12912-016-0164-4

[16] Jaradeen N, Jaradat R, Abo Safi A, et al. Students Satisfaction with Nursing Program. Matah University Jordan, Bahrain Medical Bulletin. 2012; 34(1).

[17] Frantz JM, Anthea JR. Assessing Clinical Placements in a B.Sc. Physiotherapy Program in South Africa. The Internet Journal of Allied Health Sciences and Practice. 2007; 5(3).

[18] Khanghahi ME, Fard Aza FE. Direct observation of procedural skills (DOPS) evaluation method: Systematic review of evidence. Med J Islam Repub Iran. 2018; 32: 45. PMid:30159296 https: //doi.org/10.14196/mjiri.32.45

[19] Mntambo SN. Student Nurses' Experience of Clinical Accompaniment in a Public Hospital in Gauteng Province, South Africa. 2009 Available from: http://umkn-dsp01.unisa.ac.za

[20] Sahebalzamani MFH, Jahantigh M. Validity and reliability of direct observation of procedural skills in evaluating the clinical skills of nursing students of Zahedan nursing and midwifery school. Zahedan J Res Med Sci (ZJRMS). 2012; 14: 76-81.

[21] Erfani Khanghahi M, Ebadi Fard Azar F. Direct observation of procedural skills (DOPS) evaluation method: Systematic review of evidence. Med J Islam Repub Iran. 2018; 32(1): 254-261. PMid:30159296 https ://doi.org/10.14196/mjiri.32.45

[22] Papp I, Markkanen M, von Bonsdorff M. Clinical environment as a learning environment: Student nurses perceptions concerning clinical learning experiences. Nurse Education Today. 2003; 23: 262-268. https://doi .org/10.1016/S0260-6917(02)00185-5

[23] Khosravi S, Pazargadi M, Ashktorab T. Nursing Students' viewpoints on challenges of student assessment in clinical Settings: A Qualitative Study. Iran J Educ Med. 2010; 11: 736-48.

[24] Papastavrou E, Dimitriadou M, Tsangari H, et al. Nursing students' satisfaction of the clinical learning environment: a research study. BMC Nurs. 2016; 15: 44. PMid:27436992 https ://doi .org/10 $.1186 / \mathrm{s} 12912-016-0164-4$

[25] Vaismoradi M, Parsa-Yekta Z. Iranian nursing students' comprehension and experiences regarding evaluation process: A thematic analysis study. Scand J Caring Sci. 2010; 25: 151-9. PMid:20849519 https://doi.org/10.1111/j.1471-6712.2010.00805.x

[26] Hanleya E, Higginsb A. Assessment of practice in intensive care: Students' perceptions of a clinical competence assessment tool. Intensive Crit Care Nurs. 2005; 21: 276-83. PMid:16182124 https : //doi.org/10.1016/j.iccn.2004.10.004

[27] Farajpour A, Amini M, Pishbin E, et al. Teachers' and Students' Satisfaction with DOPS Examination in Islamic Azad University of Mashhad, a Study in Year 2012. Iranian Journal of Medical Education. 2014; 14(2): 165-173.

[28] Espeland V, Indrehus O. Evaluation of Students' Satisfaction with Nursing Education in Norway. Journal of Advanced Nursing. 2003; 42(3): 226-236. PMid:12680966 https : //doi.org/10.1046/j . 1365-2648.2003.02611. $\mathrm{x}$

[29] The University of Zambia. Evaluation manual. UNZA, Zambia. 2010.

[30] Wallace B. Practical issues of student assessment. Nurs Stand. 2003; 17: 33-6. https://doi.org/10.7748/ns.17.31.33.s56

[31] University of Zambia. Progression guidelines and regulations. UNZA, Lusaka, Zambia. 2018.

[32] Sundstrom H. The characteristics of effective clinical teachers in baccalaureate nursing programs. University of Manitoba Winnipeg; 2000 . 